\title{
Attitude of Teachers on Learning Disabilities in Children
}

\author{
Ranjeetha Golde Vincent ${ }^{1 *}$ and Shobha G. ${ }^{2}$ \\ ${ }^{1}$ M.Sc. Human Development, Smt. V.H.D. Central Institute of Home Science, Karnataka, India \\ ${ }^{2}$ Associate Professor, Smt. V.H.D. Central Institute of Home Science, Karnataka, India \\ *Corresponding author: goldevincent94@gmail.com
}

Received: 14 Feb., 2020

Revised: 11 Apr, 2020

Accepted: 24 May, 2020

\begin{abstract}
The study was intended to compare the attitude of government and private school teachers of grades I-IV on learning disabilities in children. The results revealed that teachers of these schools had only moderate level of attitude towards learning disabilities in children. Further, a significant association was seen between demographic variables like monthly income, place of residence and present school experience and selected features related to learning disabilities. Significant association was observed with teachers' gender; having special training to handle children with learning disabilities; having children with learning disabilities in the classroom and the attitude level of the teachers towards the same.
\end{abstract}

Keywords: Learning disability, teacher, attitude and school

Primary levels are the most important part of a person's educational background, as it lays a strong foundation for life. Children learn about the basic skills, such as reading and writing, as well as the concepts of language, math, science and culture, among other subjects. Many of the important life lessons and skills are learnt in primary education.

The quality of teaching affects both children's social behavior and intellectual development. Going to a highly academically effective primary school gives a particular boost to very disadvantaged children. The disadvantaged children can be anyone from low socio-economic status, juvenile delinquents to children with special needs. But the question is, is our education system effective to give a particular boost to very disadvantaged children, like that of children with learning disabilities?

According to Individuals with Disabilities Education Act (IDEA), Specific Learning Disability (SPLD) is "a disorder in one or more of the basic psychological processes involved in understanding or in using language, spoken or written, which disorder may manifest itself in the imperfect ability to listen, think, speak, read, write, spell, or do mathematical calculations. Such term includes such conditions as perceptual disabilities, brain injury, minimal brain dysfunction, dyslexia, and developmental aphasia. Such term does not include a learning problem that is primarily the result of visual, hearing, or motor disabilities, of mental retardation (now known as intellectual disability), of emotional disturbance, or of environmental, cultural, or economic disadvantage."

In the light of this, the questions that arise are; can our teachers identify children with learning

How to cite this article: Vincent, R.G. and Shobha, G. (2020). Attitude of Teachers on Learning Disabilities in Children. Int. J. Peace, Edu. and Deve., 8(01): 19-32.

Source of Support: None; Conflict of Interest: None 
disabilities? Are the teachers prepared to handle the learning disabilities? Are they aware of different types of learning disabilities manifested in children? Are the teachers trained to teach children with a learning disability? Do the teachers have the conception of learning disabilities? What is the existing level of knowledge of our teachers on learning disabilities? Is there any difference in the level of knowledge about the learning disabilities among the teacher educators based on their years of experience as teacher, educational qualification, subject matter etc.? Besides, are the teachers training courses like B.Ed. etc. have any mandatory papers on, 'Special Needs Education'? Or do any of the teacher training programs in India have any special module to identify learning disabilities in children and address them? (Chatterjee and Madhusree, 2009).

In the study by Rodrigues (2008), public and private school teachers were asked what dyslexia is; some answered that dyslexia is a serious illness while others identified it as a learning disorder. For teachers who responded that it is a serious illness, they still have no idea of the problem that they deal with every day, and they need to learn about it to help their students so they do not suffer in the classroom. All teachers consider dyslexia a congenital disorder, not an acquired one. Still, when teachers were asked if they have identified students who have difficulties in the acquisition of reading and writing in school, all teachers interviewed answered yes, although some do not know what the proper procedure is for solving the problem.

An article published in Times of India, Feb 3, 2014, stated that "Accountability ranks low among teachers in India: only one headmaster reported dismissing a teacher for repeated absence, in over 3,000 government school surveyed by UNESCO. This was in sharp contrast to 35 headmasters who had sacked errant teachers, in 600 private schools under the survey. Shortage of teachers and inadequate training have also raised serious concerns. The analysis shows that not even half the schoolchildren are learning their basics well in 21 of 85 countries. Of these, 17 countries are in subSaharan Africa; the others are India, Mauritania,
Morocco and Pakistan. The only way to solve the learning crisis is to get teachers who are "trained, motivated and who enjoy teaching, who can identify and support weak learners, and who are backed by well-managed education systems."

Sawhney and Bansal (2014) observed, owing to the lack of awareness among teachers, parents and school authorities, children with learning disabilities are usually labelled as slow, behind, incapable and failure, some are beaten, punished and abused too. Studies have brought to light evidences such as, repeated failures result in low self-esteem and these children slowly stop trying to learn and achieve and eventually drop out of school.

It is saddening to come across children being labelled as failures by the society. Identifying learning disabilities early can pave the way for children to get the support they need to experience successful futures both in and out of school.

Research in this field is still in its infancy level; perhaps this situation prevails because of the inadequate knowledge in the area and lack of training. Disorders like ADHD and specific learning disabilities are prevalent in India; however, one of the major obstacles is lack of awareness of these disorders (Crawford, 2007).

Hence, the focus in this particular study is to assess government and private school teachers' (grade I to IV) attitude on learning disabilities in children.

As teachers are highly accountable in the identification of learning disabilities manifested in children and as they are also accountable in bridging the gap or rather strengthening the link with the parents too, in imparting knowledge on learning disabilities and handling children with the same. Therefore, assessing the attitude of teachers become highly relevant.

With the differences in school environment, children's profile, teachers' profile and other factors in government and private schools it is interesting and relevant to study and compare the attitude of teachers of government and private schools with respect to learning disabilities among children. Hence the study titled, 'Attitude of Teachers on Learning Disabilities in Children'is undertaken. 


\section{Methodology}

\section{Aim}

To study the Attitude of Government and Private school teachers on learning disabilities in children.

\section{Objectives}

1. To study the attitude of teachers of government and private school about learning disabilities in children.

2. To study the differences in attitude level of government and private school teachers with respect to Learning Disabilities among children.

3. To study the influence of Socio-demographic factors of teachers on the level of their attitude towards learning disabilities in children.

\section{Hypotheses}

$\odot$ H1: Government and private school teachers have the right attitude towards learning disabilities in children.

$\odot$ H2: Socio-demographic factors of the teachers influence the teachers' Attitude of learning disabilities among children.

$\odot$ H3: Government and private school teachers do not differ in the attitude related to learning disabilities among children.

\section{Limitations of the present study}

$\odot$ The study is limited to the assessment of attitude of government and private primary school teachers towards learning disabilities in children.

\section{Variables in the present study}

$\odot$ Independent Variables - Age, gender, experience, educational qualification of the teachers, marital status and number of children, subject knowledge and medium of instruction.

$\odot$ Dependent Variables - Attitude of teachers on learning disabilities in children.

\section{Questionnaire Development}

The present study consisted of a self-developed tool by the researcher, to assess the Attitude of teachers towards learning disabilities in children. The developed tool was subjected to expert validation.

The constructed tool comprised of two parts:

$\odot$ Part-A consisted of the basic data with 22 questions.

$\odot$ Part-B assessed the Attitude of teachers with respect to learning disabilities.

Attitude component comprised of 15 statements with a three-point Likert Scale 'Agree', ' Not Sure', 'Disagree' response, consisting of 8 positive statements and 7 negative statements. For the positive statements; a score of ' 2 ' for option 'agree', score ' 1 ' for option 'undecided', score ' 0 ' for disagree and the reverse order for negative statements was given. The total score obtained was 30 , the minimum score obtained was ' 0 ' and the maximum score was '30'. Higher scores indicated higher attitude levels towards learning disabilities. The attitude scores were categorized into three levels as follows:

\begin{tabular}{ll}
\hline Attitude Level & Score Ranges \\
\hline Unfavorable & $\leq 50 \%$ \\
Moderately favorable & $51-75 \%$ \\
Favorable & $>75 \%$ \\
\hline
\end{tabular}

\section{Identification of schools and selection of sample}

The sample size targeted was 80 primary school teachers, with 40 each, from government and private schools of urban Bengaluru. Eight private schools were chosen on logistic and geographical convenience basis in the north region of the city. However, the researcher had to collect the data from 24 government schools owing to most of the government schools having single teacher for the entire primary section. All the selected government schools were Kannada medium schools and the private schools were English medium schools. The sample selection included all the existing teachers of standard I-IV in the government and private schools selected. Stratified random sampling method was used in the selection of sample schools. Further 
within the selected schools the selection of samples was made using convenient sampling by selecting all the existing teachers from the eight private schools till a sample of 40 was obtained whereas 40 government school teachers were selected from 24 government schools.

\section{Pilot study}

Ten percent of the total sample size was considered for the pilot study, to know the feasibility, reliability and validity of the developed tool. The Attitude component of the tool was assessed for reliability quotient using Brown Prophecy's Split Half Method. The reliability quotient was 0.9388 for attitude component. The obtained values for Attitude showed more than 0.70 hence the tool is standardized and applicable for the main study.

\section{RESULTS AND DISCUSSION}

This section contains the basic data and findings of the quantitative data pertaining to the selfdeveloped questionnaire on Attitude of teachers towards learning disabilities in children. The findings are presented in the form of percentage scores, mean scores, ' $\mathrm{t}$ ' test and chi square test results. The findings are depicted in the form of tables and interpreted.

From table 1 it can be inferred that, all the respondents from private schools are females $(100 \%)$ while majority $(60 \%)$ of the respondents from government schools are females and the remaining being male respondents. Further with respect to age, it is seen that majority of the respondents from government schools are in the higher age category of $46+$ years ( $42.5 \%$ respondents) as against an equal percentage of the respondents from private schools in the younger age category of 21-35 years. The table further reveals that a majority $(90 \%$ and $72.5 \%$ ) of respondents from the government schools and private schools are married. With regard to the number of children, majority of respondents from the government schools and private schools have two children $(57.5 \%$ and $37.5 \%$ respectively) supporting the small family norm.

From table 2 it can be deduced that majority of respondents (50\%) from government schools receive a monthly income in the range of ₹ $26,000 /-$ to $35,000 /-$ and $92.5 \%$ of respondents from the private

Table 1: Classification of Respondents by Personal Characteristics $(\mathrm{N}=80)$

\begin{tabular}{|c|c|c|c|c|c|c|c|}
\hline \multirow{3}{*}{ Characteristics } & \multirow{3}{*}{ Category } & \multicolumn{6}{|c|}{ Respondents } \\
\hline & & \multicolumn{2}{|c|}{ Government $(n=40)$} & \multicolumn{2}{|c|}{ Private $(n=40)$} & \multicolumn{2}{|c|}{ Combined $(n=80)$} \\
\hline & & $\mathbf{N}$ & $\%$ & $\mathbf{N}$ & $\%$ & $\mathbf{N}$ & $\%$ \\
\hline \multirow[t]{2}{*}{ Gender } & Male & 16 & 40.0 & 0 & 0.0 & 16 & 20.0 \\
\hline & Female & 24 & 60.0 & 40 & 100.0 & 64 & 80.0 \\
\hline \multirow[t]{3}{*}{ Age group (years) } & $21-35$ & 9 & 22.5 & 17 & 42.5 & 26 & 32.5 \\
\hline & $36-45$ & 14 & 35.0 & 11 & 27.5 & 25 & 31.3 \\
\hline & $46+$ & 17 & 42.5 & 12 & 30.0 & 29 & 36.3 \\
\hline \multirow[t]{5}{*}{ Marital status } & Unmarried & 3 & 7.5 & 7 & 17.5 & 10 & 12.5 \\
\hline & Married & 36 & 90.0 & 29 & 72.5 & 65 & 81.3 \\
\hline & Widow(er) & 1 & 2.5 & 4 & 10.0 & 5 & 6.3 \\
\hline & Divorced/ & 0 & & 0 & & 0 & \\
\hline & Separated & & 0.0 & & 0.0 & & 0.0 \\
\hline \multirow[t]{5}{*}{ Number of children } & None & 6 & 15.0 & 13 & 32.5 & 19 & 23.8 \\
\hline & One & 7 & 17.5 & 12 & 30.0 & 19 & 23.8 \\
\hline & Two & 23 & 57.5 & 15 & 37.5 & 38 & 47.5 \\
\hline & Three & 4 & 10.0 & 0 & 0.0 & 4 & 5.0 \\
\hline & Four and above & 0 & 0.0 & 0 & 0.0 & 0 & 0.0 \\
\hline Total & & 40 & 100.0 & 40 & 100.0 & 80 & 100.0 \\
\hline
\end{tabular}




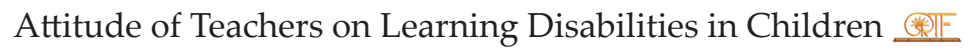

Table 2: Classification of Respondents by Related Characteristics $(\mathrm{N}=80)$

\begin{tabular}{|c|c|c|c|c|c|c|c|}
\hline \multirow{3}{*}{ Characteristics } & \multirow{3}{*}{ Category } & \multicolumn{6}{|c|}{ Respondents } \\
\hline & & \multicolumn{2}{|c|}{ Government } & \multicolumn{2}{|c|}{ Private } & \multicolumn{2}{|c|}{ Combined } \\
\hline & & $\mathbf{N}$ & $\%$ & $\mathbf{N}$ & $\%$ & $\mathbf{N}$ & $\%$ \\
\hline \multirow[t]{3}{*}{ Monthly income (₹) } & $<₹ 15,000$ & 4 & 10.0 & 37 & 92.5 & 41 & 51.3 \\
\hline & $₹ 15,000-25,000$ & 16 & 40.0 & 3 & 7.5 & 19 & 23.8 \\
\hline & ₹ 26,000-35,000 & 20 & 50.0 & 0 & 0.0 & 20 & 25.0 \\
\hline \multirow[t]{2}{*}{ Place of Residence } & Rural & 22 & 55.0 & 8 & 20.0 & 30 & 37.5 \\
\hline & Urban & 18 & 45.0 & 32 & 80.0 & 50 & 62.5 \\
\hline \multirow[t]{4}{*}{ Educational qualification } & SSLC & 8 & 20.0 & 8 & 20.0 & 16 & 20.0 \\
\hline & PUC & 9 & 22.5 & 6 & 15.0 & 15 & 18.8 \\
\hline & Degree & 17 & 42.5 & 23 & 57.5 & 40 & 50.0 \\
\hline & PG & 6 & 15.0 & 3 & 7.5 & 9 & 11.3 \\
\hline \multirow[t]{3}{*}{ Total experience (years) } & $<10$ & 7 & 17.5 & 18 & 45.0 & 25 & 31.3 \\
\hline & $10-20$ & 22 & 55.0 & 12 & 30.0 & 34 & 42.5 \\
\hline & $21+$ & 11 & 27.5 & 10 & 25.0 & 21 & 26.3 \\
\hline \multirow[t]{3}{*}{ Present school experience (years) } & $1-5$ & 14 & 35.0 & 18 & 45.0 & 32 & 40.0 \\
\hline & $6-15$ & 17 & 42.5 & 13 & 32.5 & 30 & 37.5 \\
\hline & $16+$ & 9 & 22.5 & 9 & 22.5 & 18 & 22.5 \\
\hline Total & & 40 & 100.0 & 40 & 100.0 & 80 & 100.0 \\
\hline
\end{tabular}

schools get a monthly income of less than ₹ 15,000/-. At the combined level it is seen that, majority of the respondents receive less than ₹ 15,000/- per month (51.3\%).

With respect to the place of residence, it is seen that majority of both government school and private schools' respondents are residing in urban localities, with higher percentage $(80 \%)$ of private school teachers falling in this category as against $45 \%$ of their government school counter parts. Further with respect to educational qualification of the respondents it is seen that, majority of government school and private school teacher respondents ( $42.5 \%$ and $57.5 \%$ respectively) have studied up to degree level. Twenty percent of both categories of respondents have studied up to SSLC while least percentage (15\% and $7.5 \%$ respectively) of respondents in government school and private school have studied upto PG level.

The table further reveals the total number of years of experience of the respondents. It is seen that at the combined level, majority of the respondents (42.5\%) have between 10-20 years of teaching experience with higher percentage of government school teachers $(55 \%)$ as against $30 \%$ of private school teachers falling in this category. With regard to the experience in present school; majority (42.5\%) of government school respondents have 6-15 years of teaching experience in their current schools and $45 \%$ of private schools' respondents have 1-5 years of experience in their current schools. At the combined level majority of the respondents (40\%) are found to be having 1-5 years of teaching experience in their present work place.

At the combined level in table 3, it is seen that majority of the respondents teach social studies (40\%) and mathematics (37.5\%). However, majority of the respondents of government school category (50\%) teach Kannada followed by (25\%) teach social studies and mathematics and closely followed by 22.5\% teaching English while a least percentage teaching general science, other subjects and Hindi $(12.5 \%, 10 \%$ and $7.5 \%$ respectively). In contrast majority of the private schools' respondents (55\%) teach social studies closely followed by $52.5 \%$ who teach English and Mathematics (50\%). Equal percentage of respondents of both categories taught all the subjects (15\%). Further it is seen that 
Table 3: Classification of Respondents by Related Characteristics $(\mathrm{N}=80)$

\begin{tabular}{|c|c|c|c|c|c|c|c|}
\hline \multirow{3}{*}{ Characteristics } & \multirow{3}{*}{ Category } & \multicolumn{6}{|c|}{ Respondents } \\
\hline & & \multicolumn{2}{|c|}{ Government } & \multicolumn{2}{|c|}{ Private } & \multicolumn{2}{|c|}{ Combined } \\
\hline & & $\mathbf{N}$ & $\%$ & $\mathbf{N}$ & $\%$ & $\mathbf{N}$ & $\%$ \\
\hline \multirow[t]{8}{*}{ Subjects taught } & Kannada & 20 & 50.0 & 7 & 17.5 & 27 & 33.8 \\
\hline & English & 9 & 22.5 & 21 & 52.5 & 30 & 37.5 \\
\hline & Hindi & 3 & 7.5 & 8 & 20.0 & 11 & 13.8 \\
\hline & General science & 5 & 12.5 & 11 & 27.5 & 16 & 20.0 \\
\hline & Social studies & 10 & 25.0 & 22 & 55.0 & 32 & 40.0 \\
\hline & Mathematics & 10 & 25.0 & 20 & 50.0 & 30 & 37.5 \\
\hline & Others & 4 & 10.0 & 2 & 5.0 & 6 & 7.5 \\
\hline & All subjects & 6 & 15.0 & 6 & 15.0 & 12 & 15.0 \\
\hline \multirow[t]{4}{*}{ Class taken } & Std-I & 17 & 42.5 & 13 & 32.5 & 30 & 37.5 \\
\hline & Std-II & 18 & 45.0 & 13 & 32.5 & 31 & 38.8 \\
\hline & Std-III & 21 & 52.5 & 10 & 25.0 & 31 & 38.8 \\
\hline & Std-IV & 26 & 65.0 & 15 & 37.5 & 41 & 51.3 \\
\hline Total & & 40 & 100.0 & 40 & 100.0 & 80 & 100.0 \\
\hline
\end{tabular}

Table 4: Classification of Respondents by Related Characteristics $(\mathrm{N}=80)$

\begin{tabular}{|c|c|c|c|c|c|c|c|}
\hline \multirow{3}{*}{ Aspects } & \multirow{3}{*}{ Category } & \multicolumn{6}{|c|}{ Respondents } \\
\hline & & \multicolumn{2}{|c|}{ Government $(n=40)$} & \multicolumn{2}{|c|}{ Private $(n=40)$} & \multicolumn{2}{|c|}{ Combined $(n=80)$} \\
\hline & & $\mathbf{N}$ & $\%$ & $\mathbf{N}$ & $\%$ & $\mathbf{N}$ & $\%$ \\
\hline \multirow{4}{*}{$\begin{array}{l}\text { Type of training } \\
\text { received }\end{array}$} & Classroom management & 10 & 25.0 & 17 & 42.5 & 27 & 33.8 \\
\hline & Teaching skills & 32 & 80.0 & 26 & 65.0 & 58 & 72.5 \\
\hline & Counselling & 6 & 15.0 & 18 & 45.0 & 24 & 30.0 \\
\hline & Special education & 13 & 32.5 & 5 & 12.5 & 18 & 22.5 \\
\hline \multirow[t]{4}{*}{ Frequency } & Once a year & 21 & 52.5 & 15 & 37.5 & 36 & 45.0 \\
\hline & Twice a year & 7 & 17.5 & 13 & 32.5 & 20 & 25.0 \\
\hline & Thrice a year & 3 & 7.5 & 0 & 0.0 & 3 & 3.8 \\
\hline & $>$ Thrice a year & 6 & 15.0 & 0 & 0.0 & 6 & 7.5 \\
\hline \multirow{5}{*}{$\begin{array}{l}\text { Duration of } \\
\text { training (days) }\end{array}$} & One & 2 & 5.0 & 13 & 32.5 & 15 & 18.8 \\
\hline & Two & 2 & 5.0 & 10 & 25.0 & 12 & 15.0 \\
\hline & Three & 2 & 5.0 & 4 & 10.0 & 6 & 7.5 \\
\hline & Four & 3 & 7.5 & 0 & 0.0 & 3 & 3.8 \\
\hline & More than four & 28 & 70.0 & 1 & 2.5 & 29 & 36.3 \\
\hline Total & & 40 & 100.0 & 40 & 100.0 & 80 & 100.0 \\
\hline
\end{tabular}

majority of both government school and private school respondents taught standard IV (51.3\%) and an equal percentage of respondents from both the groups taught standard II and III (38.8\% each). At the individual level, itis found that majority of the respondents from government schools taught class IV and III (65.0\% and 52.5\% respectively), while the teachers of private schools were more distributed across different classes.

Table 4 shows $80 \%$ of government school respondents received training in teaching skills, $32.5 \%$ obtained training in special education and 25\% and $15 \%$ obtained training in classroom management and counselling. With respect to private school, 65\% respondents received training in teaching skills, $45 \%$ and $42.5 \%$ in counselling and classroom management and a least percentage $(12.5 \%)$ received training in special education. At the combined level majority of the respondents $(72.5 \%)$ obtained training in teaching skills.

The findings of the study by Agnes (2010) revealed that only $29 \%$ of the teachers receive in-service 


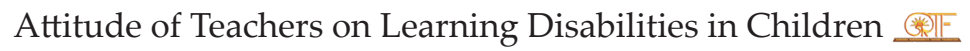

training to handle pupils with learning disabilities supports the findings of the present study where less percentage of the respondent teachers received training in special education. Concerning the frequency of trainings received $52.5 \%$ of government school respondents received training once a year. Percentage of respondents receiving training twice or more number of times in a year is less as seen in the table. Among the private school respondents, it is seen that majority $(37.5 \%)$ receive trainings once a year, which is closely followed by $32.5 \%$ receiving training twice a year. At the combined level it is seen that $45.0 \%$ of the respondents receive training once a year. With respect to the duration of training days, it is seen that $70.0 \%$ of government school respondents as against $2.5 \%$ of private school respondents receive training for more than four days. However, among the private school respondents most of the training programs are of one- or two-days duration (32.5\% and $25 \%$ respectively).

From table 5 it can be inferred that, $65 \%$ of the respondents from government schools are aware of the concept of learning disabilities as against $72.5 \%$ of respondents from private schools. Further, higher percentage of respondents from private schools and government schools said they are aware of different types of learning disabilities (52.5\% and $45.0 \%$ respectively). With respect to having special training in handling Children with learning disability in classroom, majority of the respondents from private schools and government schools $(82.5 \%$ and $77.5 \%$ respectively) did not have training, however higher percentage of respondents from government schools $(52.5 \%)$ as against $32.5 \%$ of their counterparts in private schools preferred to be trained in handling children with learning disabilities. With respect to the presence of children with learning disabilities in classroom, majority $(67.5 \%)$ of the respondents from government schools expressed that they had learning disabled children in their classes, while majority $(60 \%)$ of the respondents from private school expressed that they did not have children with learning disabilities in their classroom. Research indicates 3-10\% prevalence of learning disabilities is seen among school children (Arun, Chavan, Bhargava, Sharma and Kaur (2013)). Majority of the private school respondents not acknowledging the presence of learning-disabled children in their classrooms could be attributed to their lack of knowledge in identifying them.

Table 6 depicts the classification of respondents on attitude levels. It is seen that majority of government school respondents $(60.0 \%)$ and $67.5 \%$ respondents from private schools have moderate attitude levels as seen from the attitude scores. However, a non-significant difference is found between the two groups with respect to the attitude levels. The findings of the present study are similar to

Table 5: Classification of Respondents by Related Characteristics $(\mathrm{N}=80)$

\begin{tabular}{|c|c|c|c|c|c|c|c|}
\hline \multirow{3}{*}{ Characteristics } & \multirow{3}{*}{ Category } & \multicolumn{6}{|c|}{ Respondents } \\
\hline & & \multicolumn{2}{|c|}{ Government } & \multicolumn{2}{|c|}{ Private } & \multicolumn{2}{|c|}{ Combined } \\
\hline & & $\mathbf{N}$ & $\%$ & $\mathbf{N}$ & $\%$ & $\mathbf{N}$ & $\%$ \\
\hline \multirow[t]{2}{*}{ Aware of concept of learning disabilities } & Yes & 26 & 65.0 & 29 & 72.5 & 55 & 68.8 \\
\hline & No & 14 & 35.0 & 11 & 27.5 & 25 & 31.3 \\
\hline \multirow[t]{2}{*}{ Aware of types of learning disabilities } & Yes & 18 & 45.0 & 21 & 52.5 & 39 & 48.8 \\
\hline & No & 22 & 55.0 & 19 & 47.5 & 41 & 51.3 \\
\hline \multirow{2}{*}{$\begin{array}{l}\text { Special training on how to handle children with learning } \\
\text { disabilities }\end{array}$} & Yes & 9 & 22.5 & 7 & 17.5 & 16 & 20.0 \\
\hline & No & 31 & 77.5 & 33 & 82.5 & 64 & 80.0 \\
\hline \multirow{2}{*}{$\begin{array}{l}\text { Like to be trained to teach children with learning } \\
\text { disabilities }\end{array}$} & Yes & 21 & 52.5 & 13 & 32.5 & 34 & 42.5 \\
\hline & No & 10 & 25.0 & 20 & 50.0 & 30 & 37.5 \\
\hline \multirow[t]{2}{*}{ Children with learning disability present in classroom } & Yes & 27 & 67.5 & 16 & 40.0 & 43 & 53.8 \\
\hline & No & 13 & 32.5 & 24 & 60.0 & 37 & 46.3 \\
\hline Total & & 40 & 100.0 & 40 & 100.0 & 80 & 100.0 \\
\hline
\end{tabular}


Table 6: Classification of respondent on levels of attitude

\begin{tabular}{|c|c|c|c|c|c|c|c|c|}
\hline \multirow{3}{*}{ Attitude Level } & \multirow{3}{*}{ Category } & \multicolumn{6}{|c|}{ Respondents } & \multirow{3}{*}{$\chi^{2}$ Test } \\
\hline & & \multicolumn{2}{|c|}{ Government } & \multicolumn{2}{|c|}{ Private } & \multicolumn{2}{|c|}{ Combined } & \\
\hline & & $\mathbf{N}$ & $\%$ & $\mathbf{N}$ & $\%$ & $\mathbf{N}$ & $\%$ & \\
\hline Unfavorable & $\leq 50 \%$ Score & 0 & 0.0 & 0 & 0.0 & 0 & 0.0 & \\
\hline Moderately favorable & $51-75 \%$ Score & 24 & 60 & 27 & 67.5 & 51 & 63.8 & $0.49 \mathrm{NS}$ \\
\hline Favorable & $>75 \%$ Score & 16 & 40.0 & 13 & 32.5 & 29 & 36.3 & \\
\hline Total & & 40 & 100.0 & 40 & 100.0 & 80 & 100.0 & \\
\hline
\end{tabular}

NS: Non-Significant, $\chi^{2}(0.05,1 \mathrm{df})=3.841$.

Table 7: Overall Mean Attitude scores of Respondents $(\mathrm{N}=80)$

\begin{tabular}{|c|c|c|c|c|c|c|c|c|}
\hline \multirow{2}{*}{ Aspects } & \multirow{2}{*}{ Sample (n) } & \multirow{2}{*}{ Statements } & \multirow{2}{*}{ Max. Score } & \multicolumn{4}{|c|}{ Attitude Scores } & \multirow{2}{*}{ - 't' Test } \\
\hline & & & & Mean & SD & Mean (\%) & SD (\%) & \\
\hline Government & 40 & 15 & 30 & 21.40 & 3.7 & 71.3 & 12.5 & $0.57 \mathrm{NS}$ \\
\hline Private & 40 & 15 & 30 & 20.87 & 4.2 & 69.6 & 14.0 & \\
\hline Combined & 80 & 15 & 30 & 21.10 & 4.0 & 70.3 & 13.3 & \\
\hline
\end{tabular}

NS: Non-Significant, t $(0.05,78 \mathrm{df})=1.96$.

the findings of the study conducted by Brook, Watemberg and Geva (2000) which stated that teachers have overall moderate attitude towards learning disabilities in children.

It was hypothesized $\left(\mathrm{H}_{1}\right)$ that government and private school teachers have favorable attitude towards children with learning disabilities. However, majority of the respondents were found to be having only moderately favorable attitude and a non-significant association was found between the attitude levels and respondent categories, hence the hypothesis is rejected.

Table 7 reveals the overall mean percentage attitude scores of the respondents. The mean percentage attitude scores depicted in the table reveals that the mean percentage attitude scores of the two groups put together is $70.3 \%$ with the teachers of government schools having slightly higher attitude mean percentage scores $(71.3 \%)$ than respondents from private schools (69.6\%). However, a nonsignificant difference is seen between the two groups on this aspect. Further, it shows a non-significant association between the attitude levels and the respondents' type and a non-significant difference between the mean attitude percentage scores and the respondent types. The non-significant findings for the component attitude shows the acceptance of the formulated hypothesis.

From table 8 it can be deduced that, a significant association is found between the gender and the attitude level of the respondents with $42.1 \%$ of females having adequate level of attitude in contrast to $12.5 \%$ male respondents $\left(\chi^{2}=4.88^{*}\right)$. With reference to the age group of respondents and attitude level a non-significant association has been found with a majority of respondents in all the three age groupings having a moderate level of attitude. A non-significant association has been found with the number of children and monthly income of the respondents and their attitude levels. However higher percent of respondents from higher income category of ₹ 26,000-35,000/- have moderate level of attitude (70\%). Regarding the association between place of residence of respondents and their attitude level, a significant association has been observed with higher percentage ( $72 \%$ ) of urban respondents having moderate level of attitude and $72 \%$ of rural respondents having favorable level of attitude $\left(\chi^{2}\right.$ $\left.=3.92^{*}\right)$. Further a non-significant association is found between educational qualification, total years of teaching experience and total years of teaching years in the present school and attitude level of 


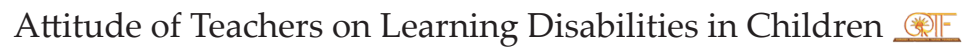

Table 8: Association between demographic variables and attitude level of respondents $(n=80)$

\begin{tabular}{|c|c|c|c|c|c|c|c|c|}
\hline \multirow{3}{*}{ Demographic Variables } & \multirow{3}{*}{ Category } & \multirow{3}{*}{ Sample } & \multicolumn{4}{|c|}{ Attitude Level } & \multirow{3}{*}{$\chi^{2}$ Value } & \multirow{3}{*}{ P-Value } \\
\hline & & & \multicolumn{2}{|c|}{ Moderate } & \multicolumn{2}{|c|}{ Favorable } & & \\
\hline & & & $\mathbf{N}$ & $\%$ & $\mathbf{N}$ & $\%$ & & \\
\hline \multirow[t]{2}{*}{ Gender } & Male & 16 & 14 & 87.5 & 2 & 12.5 & $4.88^{*}$ & $\mathrm{P}<0.05(3.841)$ \\
\hline & Female & 64 & 37 & 57.9 & 27 & 42.1 & & \\
\hline \multirow[t]{3}{*}{ Age group (years) } & $21-35$ & 26 & 17 & 65.4 & 9 & 34.6 & $0.22 \mathrm{NS}$ & $\mathrm{P}>0.05(5.991)$ \\
\hline & $36-45$ & 20 & 15 & 60.0 & 10 & 40.0 & & \\
\hline & $46+$ & 29 & 19 & 65.5 & 10 & 34.5 & & \\
\hline \multirow[t]{3}{*}{ Number of children } & None & 19 & 10 & 52.6 & 9 & 47.4 & $1.83 \mathrm{NS}$ & $\mathrm{P}>0.05(5.991)$ \\
\hline & One & 19 & 14 & 73.7 & 5 & 26.3 & & \\
\hline & Two + & 42 & 27 & 64.3 & 15 & 35.7 & & \\
\hline \multirow[t]{3}{*}{ Monthly income (₹) } & $<₹ 15,000$ & 41 & 27 & 65.9 & 14 & 34.1 & $1.43 \mathrm{NS}$ & $\mathrm{P}>0.05(5.991)$ \\
\hline & ₹ $15,000-25,000$ & 19 & 10 & 52.7 & 9 & 47.3 & & \\
\hline & ₹ 26,000-35,000 & 20 & 14 & 70.0 & 6 & 30.0 & & \\
\hline \multirow[t]{2}{*}{ Place of Residence } & Rural & 30 & 15 & 50.0 & 36 & 72.0 & $3.92^{*}$ & $\mathrm{P}<0.05(3.841)$ \\
\hline & Urban & 50 & 36 & 72.0 & 14 & 28.0 & & \\
\hline \multirow[t]{4}{*}{ Educational qualification } & SSLC+ & 16 & 10 & 62.5 & 6 & 37.5 & $0.88 \mathrm{NS}$ & $\mathrm{P}>0.05(7.815)$ \\
\hline & PUC+ & 15 & 11 & 73.3 & 4 & 26.7 & & \\
\hline & Degree+ & 40 & 24 & 60.0 & 16 & 40.0 & & \\
\hline & $\mathrm{PG}^{+}$ & 9 & 6 & 66.7 & 3 & 33.3 & & \\
\hline \multirow[t]{3}{*}{ Total experience (years) } & $<10$ & 25 & 16 & 64.1 & 9 & 36.0 & $0.89 \mathrm{NS}$ & $\mathrm{P}>0.05(7.815)$ \\
\hline & $10-20$ & 34 & 20 & 58.8 & 14 & 41.2 & & \\
\hline & $21+$ & 21 & 15 & 71.4 & 6 & 28.6 & & \\
\hline \multirow{3}{*}{$\begin{array}{l}\text { Present school experience } \\
\text { (years) }\end{array}$} & $1-5$ & 32 & 21 & 65.6 & 11 & 34.4 & $0.11 \mathrm{NS}$ & $\mathrm{P}>0.05(7.815)$ \\
\hline & $6-15$ & 30 & 19 & 63.3 & 11 & 36.7 & & \\
\hline & $16+$ & 18 & 11 & 61.1 & 7 & 38.9 & & \\
\hline Combined & & 80 & 51 & 63.8 & 29 & 36.2 & & \\
\hline
\end{tabular}

* Significant at 5\% Level, NS: Non-significant.

Note: Figures in the parenthesis indicate Table value.

the respondents. However higher percentage of respondents who were graduates, had 10-20 years of experience and about $16+$ years of experience in the current place of work had higher attitude levels. These findings can be supported with a study conducted by Bhavya, Bhavya, Chinnu, Joseph, Thomas, Prasad, and Jacob (2015) which revealed that majority of teachers (94\%) had a most favorable attitude. There was a significant association between attitude score and few demographic variables such as gender, educational qualification, child psychology in curriculum. The data revealed that there is a significant association between attitude levels of respondents with females having favorable attitude level. Further the rural respondents have higher and more favorable attitude among children with learning disabilities. The hypothesis $\left(\mathrm{H}_{2}\right)$ that the socio-demographic factors of the teachers influence the attitude of learning disabilities among children is accepted for gender and place of residence and rejected for the other demographic variables.

Table 9 shows a non-significant association between teachers undergoing regular training programs and their attitude level, however $41.5 \%$ of teachers undergoing regular trainings have favorable attitude. Concerning the association of awareness of the concept of learning disability and the attitude level, a non-significant association is observed, with $72.7 \%$ respondents having moderate level of attitude. Further a non-significant association is seen between awareness of the types of learning disabilities and the attitude level of the respondents. Seventy six percent of the respondents are found to 
Table 9: Association between selected features related to learning disabilities and attitude level of respondents $(\mathrm{n}=80)$

\begin{tabular}{|c|c|c|c|c|c|c|c|c|}
\hline \multirow{3}{*}{ Selected Features } & \multirow{3}{*}{ Category } & \multirow{3}{*}{ Sample } & \multicolumn{4}{|c|}{ Attitude Level } & \multirow{3}{*}{$\chi^{2}$ Value } & \multirow{3}{*}{ P-Value } \\
\hline & & & \multicolumn{2}{|c|}{ Moderate } & \multicolumn{2}{|c|}{ Favorable } & & \\
\hline & & & $\mathbf{N}$ & $\%$ & $\mathbf{N}$ & $\%$ & & \\
\hline \multirow{2}{*}{$\begin{array}{l}\text { School offers regular training } \\
\text { programs for teachers }\end{array}$} & Yes & 65 & 38 & 58.5 & 27 & 41.5 & $0.04 \mathrm{NS}$ & $\mathrm{P}>0.05(3.841)$ \\
\hline & No & 15 & 13 & 86.7 & 2 & 13.3 & & \\
\hline \multirow{2}{*}{$\begin{array}{l}\text { Aware of concept of learning } \\
\text { disabilities }\end{array}$} & Yes & 55 & 40 & 72.7 & 15 & 27.3 & $0.01 \mathrm{NS}$ & $\mathrm{P}>0.05(3.841)$ \\
\hline & No & 25 & 12 & 44.0 & 14 & 56.0 & & \\
\hline \multirow[t]{2}{*}{ Aware of types of learning } & Yes & 39 & 30 & 76.0 & 9 & 23.0 & $0.02 \mathrm{NS}$ & $\mathrm{P}>0.05(3.841)$ \\
\hline & No & 41 & 21 & 51.2 & 20 & 48.8 & & \\
\hline \multirow{2}{*}{$\begin{array}{l}\text { Special training on how to handle } \\
\text { children with learning disabilities }\end{array}$} & Yes & 16 & 6 & 37.5 & 10 & 62.5 & $5.96^{*}$ & $\mathrm{P}<0.05$ \\
\hline & No & 64 & 45 & 70.3 & 19 & 29.7 & & \\
\hline \multirow{2}{*}{$\begin{array}{l}\text { Children with learning disability } \\
\text { present in classroom }\end{array}$} & Yes & 43 & 23 & 53.5 & 20 & 46.5 & $4.24^{*}$ & $\mathrm{P}<0.05(3.841)$ \\
\hline & No & 37 & 28 & 75.7 & 9 & 24.3 & & \\
\hline Combined & & 80 & 51 & 63.8 & 29 & 36.2 & & \\
\hline
\end{tabular}

* Significant at 5\% Level, NS: Non-significant.

Note: Figures in the parentheses indicate Table value.

be having moderate levels of attitude. A significant association is found between teachers having special training on how to handle children with learning disabilities and the attitude level with a $\chi^{2}$ value of $5.96^{*}$. A higher percentage of respondents $(62.5 \%)$ are observed with favorable levels of attitude. A significant association with a $\chi^{2}$ value of $4.24^{*}$ is found between teachers having children with learning disabilities in their classroom and the attitude level. However, $46.5 \%$ respondents are identified having favorable levels of attitude.

\section{CONCLUSION}

The comparative study on Attitude of government and private school primary teachers on Learning Disabilities among children revealed that both the groups of teachers i.e., the government and the private school teachers had moderate attitude level on learning disabilities. The present research suggests that there is a need to offer teachers from both the groups, regular trainings on understanding learning disability among children. Trainings can be provided in the areas of teaching skills, inclusive education, intervention measures/managing children with learning disabilities in the classroom, special education, counselling, classroom habits of a teacher, etc. This will ensure that teachers are empowered thus becoming powerful, operative and competent in teaching children with different needs and handling the uniqueness of each and every child. This study recommends that there is a need for improving the attitude of teachers towards learning disabilities among children, in order to help children, benefit and get equal opportunities as their non-disabled peers.

\section{Implications of the study}

The researcher on the basis of the findings of the present study suggests that, trainings/workshops/ intervention measure for teachers are much needed in order to help them in identifying and handling children with learning disabilities in a regular classroom especially at the primary level.

\section{REFERENCES}

Agnes, G.W. 2010. Teachers awareness and intervention for primary school pupils with learning disabilities in inclusive education in Makadara Division Kenya.

Arun, P., Chavan, B.S., Bhargava, R., Sharma, S. and Kaur, J. 2013. Prevalence of specific developmental disorder of scholastic skill in school students in Chandigarh, India. The Indian Journal of Medical Research, 138(1): 89-98. 
Bhavya., Bhavya, S., Chinnu, C.M., Joseph, C.E., Thomas, D., Prasad, C.V. and Jacob, V. 2015. The knowledge and attitude of teachers regarding specific learning disabilities among children: A descriptive approach. International. Journal of Recent Scientific Research, 6: 2536-2541.

Crawford, as cited in Kamala and Ramganesh, 2013, pp. 2.

Kamala, R. and Ramganesh, E. 2013. Knowledge of specific learning disabilities among teacher educators in Puducherry, Union Territory in India. International Review of Social Sciences and Humanities, 6: 168-175.

Madhushree and Chatterjee, as cited in Kamala and Ramganesh, 2013, pp. 6.

Rodrigues, as cited in Thaís dos Santos Gonçalves and Patrícia Abreu Pinheiro Crenitte, 2014.
Thaís dos Santos Gonçalves and Patrícia Abreu Pinheiro Crenitte. 2014. Conception of elementary school teachers about learning disorders. Speech, Language, Hearing Sciences and Education Journal, 16(3).

Ullas, S.S. 2014. What India needs: Trained, motivated teachers. Times of India. Retrieved from https:// timesofindia.indiatimes.com/city/bengaluru/What-Indianeeds-Trained-motivated-teachers/articleshow/29796050. $\mathrm{cms}$

Uzi Brook, U., Watemberg, N. and Geva, D. 2000. Attitude and knowledge of attention deficit hyperactivity disorder and learning disability among high school teachers. Patient Education and Counseling, 40(3): 247-252. 


\section{Appendix}

\section{Developed questionnaire on "Attitude of teachers on learning disabilities in children"}

Dear Respondents

Kindly fill in the questionnaire. The information collected for a study through this questionnaire will be kept confidential and will be used only for research purpose. Please ensure you fill in all the questions.

Thank you.

PART A - BASIC DATA

1 Name of the school

Type of school

(a) Private

(b) Government

(c) Aided

Nature of school

(a) All girls

(b) All boys

(c) Co-education

Syllabus followed

(a) SSLC

(b) CBSE

(c) ICSE

Medium of instruction

(a) English

(b) Kannada

(c) Any other

2 Name of the teacher

Gender

(a) Male

(b) Female

\begin{tabular}{lll}
\hline 3 Age (years) & \\
\hline Marital status & (a) Unmarried \\
& (b) Married & (c) Widow (er) \\
& (d) Divorced /Separated \\
\hline Number of children & (a) None \\
& (b) One \\
& (c) Two \\
& (d) Three \\
\hline Monthly income (₹) & (e) Four \& above \\
\hline Place of residence & (a) Rural \\
& (b) Urban
\end{tabular}

Educational qualification

Subjects taught

Total years of teaching experience

Years of teaching in the present school 


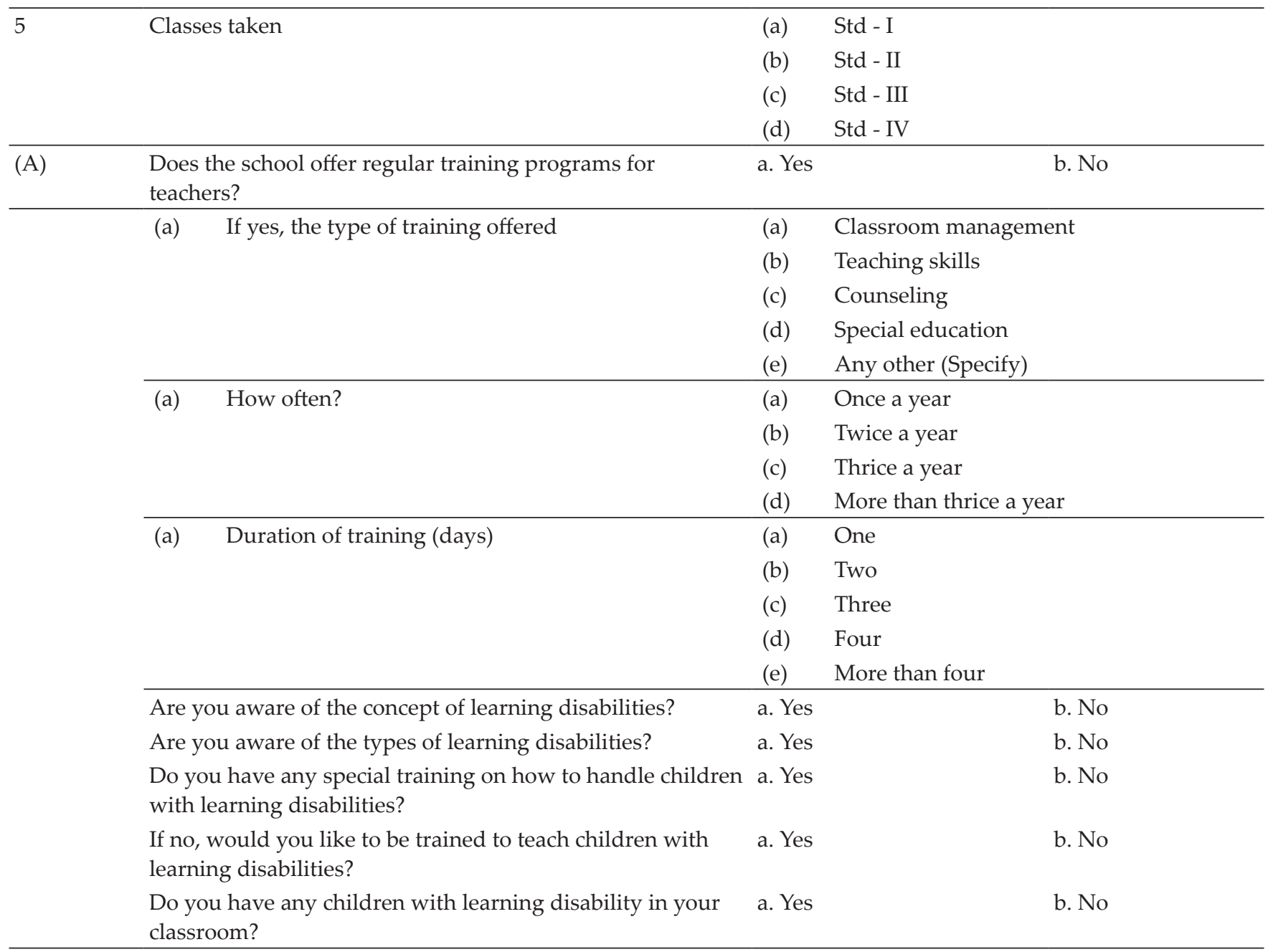

\section{PART B - SPECIFIC DATA}

\begin{tabular}{|c|c|c|c|c|}
\hline \multirow{2}{*}{ Sl. No. } & \multirow{2}{*}{ Statements on Attitude } & \multicolumn{3}{|c|}{ Response } \\
\hline & & Agree & Undecided & Disagree \\
\hline 1 & Learning disabilities is indicative of low intelligence. & & & \\
\hline 2 & $\begin{array}{l}\text { A child who seems intelligent and capable but is not } \\
\text { performing well in academics has learning disabilities. }\end{array}$ & & & \\
\hline 3 & $\begin{array}{l}\text { A child who scores good marks in all the subjects in } \\
\text { one exam, scores poorly in the next exam has learning } \\
\text { disabilities. }\end{array}$ & & & \\
\hline 4 & $\begin{array}{l}\text { A child who secures good scores in certain subjects and } \\
\text { poor scores in remaining subjects could be having learning } \\
\text { disabilities. }\end{array}$ & & & \\
\hline 5 & $\begin{array}{l}\text { Children with learning disabilities have difficulty in } \\
\text { achieving because of deficient brain functioning. }\end{array}$ & & & \\
\hline 6 & $\begin{array}{l}\text { There is a need for greater understanding of learning } \\
\text { disability among parents, educators and the society. }\end{array}$ & & & \\
\hline 7 & $\begin{array}{l}\text { Children can learn to compensate for a learning disability } \\
\text { with proper instruction. }\end{array}$ & & & \\
\hline
\end{tabular}


$8 \quad$ Children with learning disabilities are just as smart as you and me.

9 A learning-disabled child is mentally retarded and autistic.

10 Learning disabilities are often due to the kind of home environment in which children are raised.

11 Learning disabilities are the result of laziness.

12 Every child is capable of learning.

13 Children with learning disability have lower confidence level in their ability to learn.

14 They are capable of doing even better in certain tasks than children without learning disabilities.

15 Learning disability is associated with increased risk for mental health problems like anxiety, depression and low self-esteem.

\section{Thank you!}

\section{Funding}

This research did not receive any specific grant from funding agencies in the public, commercialor not-forprofit sectors. 